\title{
Molecularly imprinted electrochemical sensor for the detection of bisphenol A
}

\author{
Benzhi Liu ${ }^{1,2, *}$, Jinlong Yan $^{2}$, Min Wang ${ }^{2}$, Xiangyang Wu ${ }^{1, *}$ \\ ${ }^{1}$ School of Environment and Safety Engineering, Jiangsu University, Zhenjiang, Jiangsu Province, \\ China, Postcode: 212013. \\ ${ }^{2}$ School of Environmental Science and Engineering, Yancheng Institute of Technology, Yancheng, \\ Jiangsu Province, China, Postcode: 224051. \\ *E-mail: benzhiliu@163.com (B. Liu); wuxy@ujs.edu.cn (X. Wu)
}

doi: $10.20964 / 2019.04 .58$

Received: 8 January 2019 / Accepted: 13 February 2019 / Published: 10 March 2019

The imprinted electrochemical sensor was fabricated to determine bisphenol A by differential pulse voltammetry. Under the optimal condition, the proposed sensor exhibited a well linear relationship toward the bisphenol A concentrations in the range of 0.2 to $45 \mu \mathrm{M}$, with a detection limit of $0.03 \mu \mathrm{M}$ and a correlation coefficient of 0.9965 . The proposed sensor possessed high selectivity and sensitivity to bisphenol A detection, which was successfully applied to detect bisphenol A in real samples. The recoveries were in the range of $92.7-96 \%$.

Keywords: Molecularly imprinted polymers, Electrochemical sensor, Bisphenol A

\section{$\underline{\text { FULL TEXT }}$}

(C) 2019 The Authors. Published by ESG (www.electrochemsci.org). This article is an open access article distributed under the terms and conditions of the Creative Commons Attribution license (http://creativecommons.org/licenses/by/4.0/). 